\title{
ON THE PRESENCE OF ARSENIC IN THE ATMOSPHERE.
}

By H. C. Bartlett, Ph.D., \&c.

Having been very anxious to ascertain if arsenic in any form can be detected in the atmosphere of a room papered with arsenical wall paper, I have made a series of preliminary experiments which appear to prove that this highly important object can be satisfactorily accomplished.

I. I first took a large glass jar, in which I placed three square yards of wall paper, 
known to be free from arsenic and antimony. I then passed a gentle stream of pure hydrogen, obtained from the gradual decomposition of sodium amalgam, through the jar, directing the jet of gas upon a filter paper moistened with very slightly acid silver nitrate. When this experiment was conducted in complete darkness, or with the assistance of completely non-actinic light, no reaction took place during an exposure of twelve hours.

II. Repeated this experiment, after passing a small quantity of ammoniacal gas through the jar, with the same result as before.

III. This time I varied the experiment by producing the hydrogen by the decomposition of zinc in dilute sulphuric acid. After twelve hours a slight stain on the filter paper induced me to continue, greatly increasing the quantity of hydrogen passing through the jar. A deep brown mark then resulted. This was very unsatisfactory, as both the zinc and the acid appeared to be free from arsenic and antimony when tested by Marsh's process.

IV. My next attempt was to substitute aluminium and pure potassic hydrate for the acid, and afterwards magnesium for the zinc, and when no actinic light fell upon the nitrate of silver paper no discolouration took place. I therefore assume that my samples of zinc, or sulphuric acid, contained a trace of arsenic too minute to be detected by Marsh's test, but sufficient to give a strong reaction with ammoniacal silver nitrate.

V. Taking the same quantity of wall paper as in the previous experiments, but selecting one coloured with a large quantity of arsenical pigment, I moistened the back of the paper slightly, and then passed a little ammoniacal gas through the jar. The hydrogen from sodium amalgam being the purest and most easily available, I chose this, and I am happy to say that in each of the three experiments so carried out there has been a characteristic reaction, proving to my mind conclusively that arsenic in a gaseous or pulverulent form, emanating from wall paper, can be detected.

I am now about to try a long continuous experiment of passing pure hydrogen with a trace of ammonia over the surface of 20 square yards of paper in the hope of being able to collect the resulting arsenious compounds of silver salt (arsenite of silver).

MiLk of Ruxrnasts.-In all probability there has not been sufficient attention, thinks Dr. Brush, drawn to the differences existing between the milk of animals who ruminate, as the cow, and those who do not chew the cud, as the ass and the horse; and he would divide milk into two classes-that which is the product of cud-chewing, and that which is the product of non-cud-chewing animals. The milk of the cud-chewers contains a variety of caseine, which, under the action of the digestive process, coagulates into a hard mass. Contrary to the often-expressed belief, he declares that this coagulation takes place in the ordinary process of digestion in the calf. He had one tied up, out of the reach of any food, and had it fed with freshly-drawn cow's milk. Half an hour after its meal, he always found it busily chewing the cud. After many inquiries, he has ascertained that the same takes place with the sheep and the goat ; and from these facts, he is inclined to explain the difficulty often experienced by the human stomach in properly digesting the milk of ruminating animals. The other variety of milk, to which human, equine, and asses' milk belong, does not under the action of acids in the same way coagulate into the hard mass that is found in cows' milk, but coagulates rather into small granular or flocculent masses, which are easily diffusible. This would explain why Kumyss prepared from cows' milk is found to agree better with children than cows' milk itself; the Kumyss has been, so to speak, already chewed. In the milk of the cud-chewers there is but a small amount of sugar and a large amount of caseine, while exactly the reverse of this is the case with the milk of the non-cud-chewers; and in this fact there is again a reason why the milk of the latter, at least in the case of children who cannot get their natural supply, is to be preferred. It will be remembered that Kumyss is a beverage prepared by the people of Yakutz from mares' milk, and found to be highly nutritious, but that the beverage referred to by Dr. Brush is a product artificially preparea from cows' mill. 